Article

\title{
Involvement of Epigenetic Mechanisms in Herbicide Resistance: The Case of Conyza canadensis
}

\author{
Theoni Margaritopoulou ${ }^{1}$ (D), Eleni Tani ${ }^{2, *}$, Demosthenis Chachalis ${ }^{1}$ and Ilias Travlos ${ }^{2}$ \\ 1 Laboratory of Weed Science, Benaki Phytopathological Institute, S. Delta 8, 14561 Athens, Greece; \\ theonimarg@yahoo.gr (T.M.); dchachalis@hotmail.com (D.C.) \\ 2 Department of Crop Science, Agricultural University of Athens, IeraOdos75, 11855 Athens, Greece; \\ travlos@aua.gr \\ * Correspondence: etani@aua.gr; Tel.: +30-210-529-4625
}

Received: 15 November 2017; Accepted: 17 January 2018; Published: 22 January 2018

\begin{abstract}
Glyphosate is the most important herbicide globally, and horseweed (Conyza canadensis) has been one of the most commonly encountered weed species that has developed resistance to it in various parts of the world, including Greece. After glyphosate application, horseweed populations show a wide range of phenotypic plasticity in response to selection pressure. In previous work, we have proposed a herbicide resistance mechanism that is not due to a point mutation at the codon 106 of EPSP synthase but most likely due to a synchronized overexpression of EPSPS and the $A B C$ transporter genes. In the current study, it is hypothesized that the observed phenotypic alterations and differential expression of the EPSPS gene could be attributed to epigenetic changes. DNA methylation plays a pivotal role in many biological procedures such as gene expression, differentiation, and cellular proliferation. Sodium bisulfite sequencing was used to detect epigenetic changes that occur at the C5 position of cytosine residues within CpGdi nucleotides in two horseweed populations (resistant vs. susceptible). Results show differential methylation pattern between the two populations. This work will elucidate the naturally increased resistance of $C$. Canadensis to glyphosate and set the bases for future development of techniques that restrict weed resistance to herbicides.
\end{abstract}

Keywords: glyphosate resistance; Conyza canadensis; EPSPS; epigenetics

\section{Introduction}

Glyphosate is considered the world's most important herbicide. However, its prolonged use has resulted in the appearance of several biotypes of diverged weeds that have evolved resistance to the herbicide [1].

The study of resistance mechanisms in different weed species has provided valuable information regarding the evolutionary processes of weed species which were trying to combat intense selection pressure. Target-site resistance (TSR) is fulfilled by amino-acid substitutions at one of several possible positions on the herbicide target protein, causing a reduction in the efficacy of the direct action of the herbicide on its target [2-5]. Target-site mutations for glyphosate resistance are apparently rare within weed populations and not very efficient, whereas target-site mutations occurring for some other herbicides endow high levels of resistance [6]. Additionally, the recently rapid increase in the abundance and geographical extent of herbicide resistance is largely due to nontarget-site-based resistance (NTSR) which is of complex multigenic control $[7,8]$ and cannot be explained by models used to investigate TSR. NTSR mechanisms include reduced translocation [9], vacuolar glyphosate sequestration [10], gene amplification [11], and rapid mature leaf necrosis resulting in reduced translocation $[12,13]$.

Different glyphosate resistance mechanisms occur within populations and within individuals [14]. Several studies have already reported the synergy of both Transcriptional gene silencing (TGS) and 
Non-target-site resistance (NTSR) mechanisms in order to provide higher-level of resistance [15-17]. Accumulation of multiple mechanisms is a common trend, particularly in cross-pollinated species, resulting in higher resistance levels in response to continuing glyphosate selection pressure. Consequently, efficient weed management becomes even more challenging and should utilize additional methods in order to control glyphosate-resistant weeds [18,19]. Several 'omics' approaches could help elucidating the genetic bases of complex resistances, e.g., transcriptomes are already available for several broadleaved weed species [20-22].

On the other hand, mutations are changes in a DNA sequence that can influence either TSR, causing an increase in the expression of the herbicide target protein that compensates for the herbicide inhibitory action, or NTSR by creating a variation in the expression of herbicide-metabolizing enzyme(s) or of transporter proteins that will lead to an increase in herbicide degradation or translocation, respectively [22]. Epigenetic processes (e.g., DNA methylation or histone modifications) can also be involved in the regulation of gene expression [23,24]. These modifications are not mutations in the DNA sequence, but they are transmitted to the progeny of the plant. In particular, herbicide stress is a kind of abiotic stress and triggers regulation cascades that can lead to herbicide 'stress imprint' by epigenetic modifications [24].

The epigenetic effects have the adaptive advantage of directly transmitting the 'stress imprint' of mother plants to the next generation as a pre-regulated expression pattern, without the need for mutations in regulator genes to occur, and can have a major impact on the organism capacity to respond quickly and establish a long-term stress adaptation $[25,26]$. Although several examples have pinpointed the potential role of cultivar-specific DNA methylation patterns as an important regulatory mechanism for sensing and responding to the stress conditions via modulation of stress-responsive genes [27,28], only a few have mentioned the implication of the aforementioned mechanisms or spontaneous mutations in the evolvement of herbicide resistance. In earlier works [29], they reported that the resistant goosegrass (Eleusineindica L.) biotype to dinitroaniline herbicides contains a base changes within the coding sequence of a major a-tubulin gene which is most probably due to a spontaneous deamination of methylated cytosine. Moreover, the rapid evolution of herbicide resistance in palmer amaranth (Amaranthuspalmeri S. Wats.) due to multiple copies of the EPSPS genes suggests that epigenetic responses to a changing environment based on alterations in genome architecture rather than changes in the underlying DNA base sequence could explain at least some of its capacity to adapt rapidly [30].

In our previous study, we showed that glyphosate resistance in Conyza canadensis, one of the most problematic weeds in terms of management in Mediterranean basin, was conferred through the synchronization of two resistance mechanisms, the overexpression of EPSPS gene and the simultaneous abundance of $M 10, M 11 A B C$ transporters gene transcripts [17]. Due to the fact that EPSPS altered expression between resistant and susceptible biotypes was not conferred due to a point mutation, with this study, we aim to unravel the possible involvement of an epigenetic mechanism (i.e., the levels of DNA methylation of the EPSPS1 gene in one resistant and one susceptible C. canadensis biotype) which could contribute to this phenomenon.

\section{Materials and Methods}

\subsection{Plant Material and Growth Conditions}

Horseweed seeds of two biotypes (progeny) previously confirmed and characterized as glyphosate resistant (R) and susceptible (S) were included in the present study [31]. The R biotype was from a citrus orchard with a long history of glyphosate use (more than 20 years) and 2-3 applications per year (Lakoniaprefecture). The S biotype's origin was from an olive orchard in Attiki prefecture that had never been treated with glyphosate and therefore was used as our reference susceptible population.

Fifty seeds from each biotype were sown in separate $12 \times 13 \times 5 \mathrm{~cm}$ pots. An herbicide-free soil from Agricultural University of Athens (AUA) mixed with a common peat substrate $(1: 1, v / v)$ 
was used. Throughout the experiments, the pots were uniformly watered as needed and supplied with $50 \mathrm{~mL} /$ pot of modified Hoagland's solution (0.25\%) every 10 day [32]. Seeds were placed on the substrate surface and watered. Pots were maintained in natural conditions with a photoperiod of $12-14 \mathrm{~h}$ and air temperatures in the range of $19-32{ }^{\circ} \mathrm{C}$. Seedlings at the three- to five-leaf stage were transplanted into individual pots $(15 \mathrm{~cm}$ diameter by $30 \mathrm{~cm}$ depth), using the same substrate.

\subsection{Herbicide Treatment}

Experiments were conducted on true type plants either R- (resistant) or S- (susceptible) based on previous pre-selection during other experiments [31]. When horseweed seedlings were at the rosette stage (5-10 cm diameter, 6-10 leaves), they were sprayed with $0.72 \mathrm{~kg}$ ae/ha of glyphosate (Roundup Gold 36SL) (maximum recommended rate) using a custom-built, compressed-air, low pressure flat-fan nozzle experimental sprayer delivering herbicide in $300 \mathrm{~L} /$ ha water at $250 \mathrm{kPa}$. The experiment was conducted twice. Plants were left to full developmental stage after glyphosate application (60 DAP, Days After Application) to manifest clear resistance symptoms (all plants were either resistant or susceptible). The S-plants were measured (95\% control) to be effectively controlled, whereas the R-plants ( $22 \%$ control) were uncontrolled by the above glyphosate rate. As a standard procedure, all screening experiments routinely measured the shikimate as a biochemical screening test for glyphosate resistance [31]; the R-plants had a very low level of shikimate similar to the untreated control plants (data not shown) to further support that the used R-plants were true type glyphosate resistant ones.

\subsection{DNA Isolation and Bisulfite Sequencing}

Genomic DNA was isolated from 60-day-old leaves of the previously mentioned Conyza canadensis populations with the Nucleospin Plant II (Macherey Nagel, Düren, Germany) according to the manufacturer's instructions. DNA concentrations were determined spectrophotometrically and verified by ethidium bromide staining on agarose gels (Merck, Darmstadt, Germany). Approximately $500 \mathrm{ng}$ of purified genomic DNA was used for bisulfite conversion with the EpiTect Bisulfite Kit (Qiagen, Kopenhagen, Denmark) manufacturer's instructions.

The sequence of interest was PCR (Eppendorf, Hamburg, Germany) amplified from the Bisulfite-treated DNA with a set of appropriate primers (EpspsBi-F: TATGAAATTTTGTTTTT and EpspsBi-R: CARAAACTATTAAACATTTTTTT). The amplified fragments were cloned into the pGEM-T easy vector (Promega). Around 20 individual clones were randomly selected and plasmid DNA was isolated and sequenced. The ratio of methylated to unmethylated sites was determined and the data were presented as percentages according to $100 \times C /(C+T)$.

\subsection{Statistical and In Silico Analysis}

For the statistical analysis of measurements the SPSS (IBM statistics v.20, IBM cooropration, New York, NY, USA) program was used. In silico analysis of the EPSPS DNA fragment was performed using the PlantCare database (http:/ /bioinformatics.psb.ugent.be/webtools/plantcare/ $\mathrm{html} /$ ), the Jaspar database (http://jaspar.genereg.net/cgi-bin/jaspar_db.pl? rm=browse\& db=core\& tax_group=plants) and the PLACE database (http:/ / ppdb.agr.gifu-u.ac.jp/ppdb / cgi-bin/all_place_ motif_list.cgi?organism=At).

\section{Results}

\subsection{Differential Epigenetic Landscape in $R$ and $S$ Populations of Conyza canadensis}

The application of glyphosate in the $\mathrm{R}$ and $\mathrm{S}$ populations showed that the $\mathrm{R}$ population has developed a resistance mechanism that enables horseweed to withstand even high concentrations of glyphosate. Recent findings have shown that between the two populations there is a differential expression of the EPSP-synthase 1 gene [17]. These differences are not relying on the mutation on 
the proline 106 of the gene's nucleotide sequence. Moreover, the two populations have been shown to present modified patterns of shikimate accumulation [17].

These data prompt us to consider that there are epigenetic modifications affecting EPSP-synthase 1 gene expression between the $\mathrm{R}$ and $\mathrm{S}$ populations. Sequenced EPSPS1 gene from both resistant and susceptible biotypes did not reveal any change in its nucleotide sequence (data not shown). Thus the modifications could be due to the presence of methylgroups on the cytosine residues of the gene's nucleotide sequence. In order to uncover the presence of these epigenetic modifications, sodium bisulfite sequencing was performed on a specific genomic region of the EPSP-synthase 1 gene that contains the translation start site (Figure 1). Analysis of the methylated versus un-methylated cytosine residues of the DNA sequence between the two samples showed us that in the R population the levels of the methylated cytosine residues were higher (average value of $31.1 \%$ ) than the comparable ones on the S population (mean value 16.1\%) (Figure 2). Even though some cytosine residues were over-methylated in the S population compared to R population (e.g., cytosine residue position 275; $71.5 \%$ in $S$ versus $33.5 \%$ in $R$ ), the majority of the residues were over-methylated in the R population $(33.5-45 \%)$ versus low methylation profiles in the S population (28\%) (Figure 2).

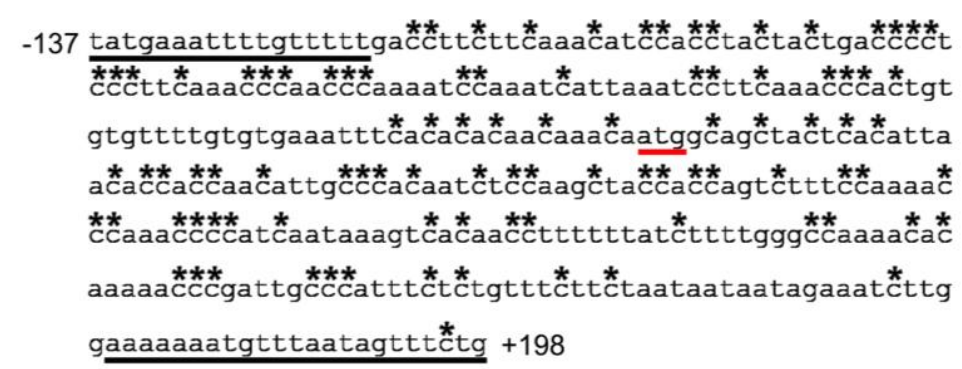

Figure 1. Nucleotide sequence of the genomic DNA fragment of the EPSP-synthase 1 gene of Conyza canadensis. Bases are numbered relative to the translation start site (red line) at position +1 . Cytosine residues are marked with asterisks. Black solid lines indicate the primers used for amplification and sequencing.
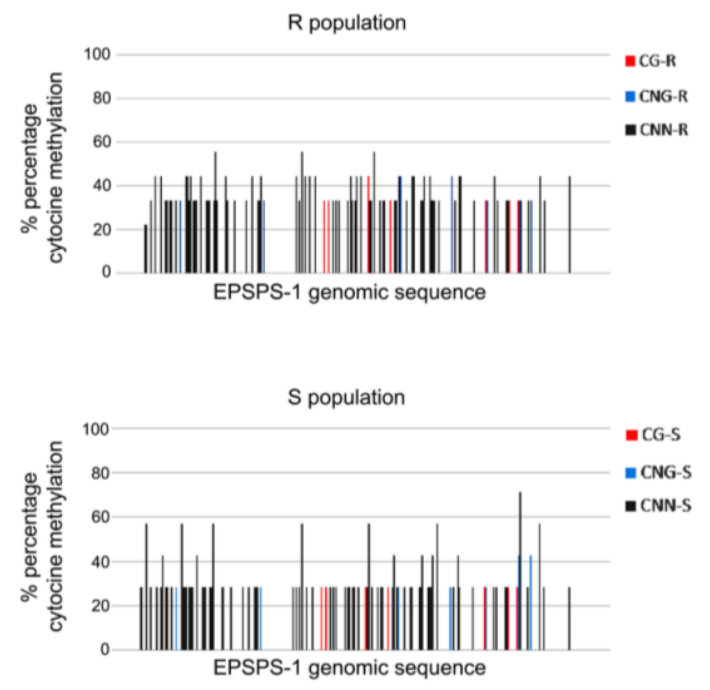

Figure 2. Bisulfite sequencing data shown as percentage methylation in $\mathrm{CG}, \mathrm{CNG}$, and $\mathrm{CNN}$ islands of the genomic DNA fragment of the EPSP-synthase 1 gene of Conyza canadensis. Vertical lines indicate the positions of cytosines. The height of each line represents the percentage of $5^{\prime}-\mathrm{Me}-\mathrm{C}$ at that position. The horizontal line of the $x$-axis on each graph represents the DNA sequence of the EPSP-synthase 1 gene. S population: susceptible population; R population: resistant population. 
The differential methylation pattern was even more obvious when the total methylation percentage was assessed for each CG, CNG, and CNN island (Figure 3). Even though the methylation pattern on the CG islands showed low variation between the two populations $(28 \%$ in $\mathrm{S}$ versus $33.5 \%$ in $\mathrm{R}$ population), there was an increase in the variation of the methylation pattern in CNG islands and an even greater variation in $\mathrm{CNN}$ islands $(28-33 \%$ in $\mathrm{S}$ versus $33.5-45 \%$ in $\mathrm{R} ; 28 \%$ in $\mathrm{S}$ versus $33.5-57 \%$ in $\mathrm{R}$ respectively). On the contrary, only a small number of CNN islands displayed very low methylation changes in the R population in the onset of the tested DNA sequence (22\%, Figures 2 and 3 ).

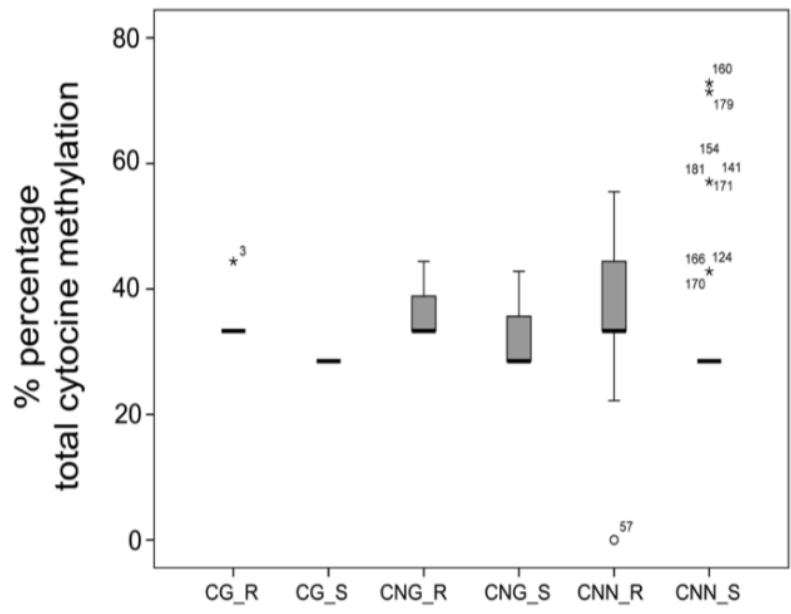

Figure 3. Total cytosine methylation changes for the $C G, C N G$, and $C N N$ islands of the genomic sequence of the EPSP-synthase 1 gene for the $\mathrm{S}$ and $\mathrm{R}$ populations. Each boxplot represents the percentage of $5^{\prime}-\mathrm{Me}-\mathrm{C}$ at each island, respectively. ${ }^{*}$ represents extreme values more than $3.5 \times$ of the interquartile range of the box which contains the middle $50 \%$ of the records, ${ }^{\circ}$ represents extreme values more than $1.5 \times$ of the interquartile range of the box.

\subsection{Various Cis-Acting Elements Are Present on Conyza canadensis Nucleotide Sequence}

Since the results showed that the genomic sequence of the EPSP-synthase 1 gene had differential methylation pattern between the two populations, we attempted to identify cis-acting elements that could be affected by the presence of methyl-groups on the cytosine residues. Conyza canadensis is not a fully sequenced organism and although it is a weed of great economic importance, we still have limited knowledge regarding its genome sequence. Therefore, we performed in silico analysis in databases which contain information of cis-acting elements of interrelated or model organisms in order to uncover similar elements on EPSP-synthase 1 gene's genomic sequence. As it is shown on Figure 4, the analyzed genomic sequence contains at least four different consensuses. The search revealed four CAAT-boxes that are related with promoter efficiency, two different elements that are related with light responsiveness; one element that is related with the binding of MADS-box transcription factors which regulate vegetative phase change, flowering time, branching, and leaf initiation rate; and one element that is related with abscisic acid and stress response. These bioinformatic data showed that the analyzed genomic region has significant importance for the EPSP-synthase 1 gene's expression and subsequent pathway regulation. 
tatgaaattttgtttttgaccttcttcaaacatccacctactactgacc

Sp1 (Zea mays)

Light responsiveness

caat-boxes

cctccettcaaacccaacccaaatccaatcattaatccttcaaacc

cactgtgtgttttgtgtgaaatttcacacacaacaacaatggcagcta

ctcacattaacaccaccaacattgcccacaatctccaagctaccaccag

WRKY40 (Arabidopsis thaliana)

Abscisic acid and abiotic stress

response

tctttccaaacccaaaccccatcaataagtcacaacctttttatct

tttgggccaaaacacaaaacccgattgcccatttctctgtttcttcta

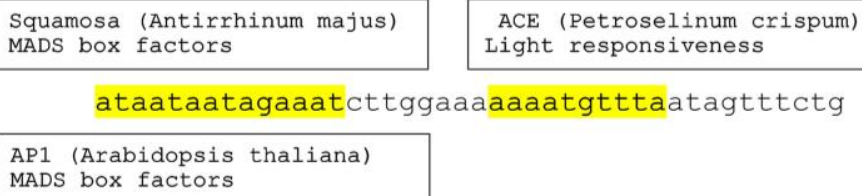

Figure 4. In silico analysis of the DNA sequence of the EPSP-synthase 1 gene of Conyza canadensis. Black solid lines represent the CAAT-boxes and yellow markers represent the elements found in the sequence. The red line represents the translation start site. Sp1: light responsiveness element; WRKY40: WRKY-domain transcription factor, ACE: light responsiveness element; AP1: APETALA 1 transcription factor.

\section{Discussion}

Weed resistance to herbicides is rapidly increasing worldwide and threatening crop security through enormous pesticide application [1]. The understanding of the genetic bases and evolutionary mechanisms of herbicide resistance is of great interest in order to highlight the complex nature of this adaptive trait and reveal potential solutions. Even though target-site-resistance can confer and, many times, explain resistance to herbicides $[15,16]$ the recent rapid increase in the abundance and geographical extent of herbicide resistance is largely due to non-target-site resistance which is of complex multigenic control [3,6,10,19].

Epigenetic processes can be also involved in the regulation of gene expression [24]. Consequently, in the presence of either regulatory mutations or epigenetic regulations, the investigation and detection of herbicide resistance is mostly achieved by analyzing significant differences in the expression of genes between resistant and sensitive populations [22].

Conyza canadensis is one of the most challenging weeds to manage in the Mediterranean basin because of its established resistance to glyphosate [33]. In order to elucidate the resistance mechanism of horseweed to glyphosate, we examined the presence and variation of epigenetic modifications on one resistant (R) and one susceptible (S) population. The results of the bisulfite sequencing showed considerably interesting findings. The nucleotide sequence of the EPSP-synthase 1 gene encompassing the translation start site was more methylated in the R population than the $\mathrm{S}$ one. Previous results [34] have shown that in $\mathrm{R}$ population the expression of the EPSP-synthase 1 gene is increased. Combining the recent findings, we speculate that the increased expression of the gene is correlated with its increased methylation status.

There is evidence for a mechanistic relationship between DNA methylation of the transcribed region of a gene and the regulation of its expression in a positive correlated manner [35-37], demonstrating a novel role of gene body methylation in the eukaryotic genomes. Methylation 
in the body of the gene does not block and could even stimulate transcription elongation [36]. Literature suggests that body methylation is predominately distributed in exons and enhances accurate splicing of primary transcripts [37-40]. Findings indicate that DNA methylation within the body of Arabidopsis genes is a key factor that may determine or negatively influence the capacity of genes to respond to internal or external stimuli (regulation of gene expression) [35]. For example, ASR1 gene of tomato is upregulated during drought stress due to higher GC methylation levels in the first exon of the gene [41]. Linking the acquired information with our results in the differential methylation pattern between the two horseweed populations, there appears to be a good probability that the increased body methylation of EPSP-synthase 1 gene in R population, could affect positively its expression and therefore Conyza canadensis resistance to glyphosate. Even though our results are preliminary, they set a sufficient base for further research to understand and clarify glyphosate resistance in Conyza canadensis.

Epigenetic processes are involved in the regulation of stress responses $[3,23,42]$ and the application of herbicides is one of them. Transmission of pre-regulated expression patterns to the progeny of plants having survived herbicide stress without the need for mutations could accelerate the evolution of resistance. This topic opens entirely new research avenues for studies of herbicide resistance.

\section{Conclusions}

The plethora of herbicide resistance mechanisms as well as the rapid increase of weeds resistant to herbicides have multiplied the difficulties that scientists face in order to provide a well- organized weed control. On the other hand epigenetic mechanisms can alter the response of plants to adverse environmental factors and can contribute to their stress adaptation. Additionally, there are several findings supporting the idea that herbicides can induce epigenetic responses. If epigenetic effects are triggered by herbicide treatment, this will result in fast 'memory' to herbicide treatments and it will consequently fasten the evolution of resistance, particularly NTSR. Our results provide evidence that such epigenetic effects after herbicide treatment do exist and should be studied more thoroughly in the future for more efficient weed management.

Acknowledgments: The authors wish to thank Danai Poulidi for her comments on the manuscript.

Author Contributions: Theoni Margaritopoulou performed the experiments, analyzed the data, and wrote the manuscript. Eleni Tani, Demosthenis Chachalis, and Ilias Travlos conceived the experiment, analyzed the data, and wrote the manuscript.

Conflicts of Interest: The authors declare no conflict of interest.

\section{References}

1. Heap, I. Global perspective of herbicide-resistant weeds. Pest Manag. Sci. 2014, 70, 1306-1315. [CrossRef] [PubMed]

2. Dayan, F.E.; Daga, P.R.; Duke, S.O.; Lee, R.M.; Tranel, P.J.; Doerksen, R.J. Biochemical and structural consequences of a glycine deletion in the $\alpha-8$ helix of protoporphyrinogen oxidase. BBA Proteins Proteom. 2010, 1804, 1548-1556. [CrossRef] [PubMed]

3. Délye, C.; Jasieniuk, M.; Le Corre, V. Deciphering the evolution of herbicide resistance in weeds. Trends Genet. 2013, 29, 649-658. [CrossRef] [PubMed]

4. Avila-Garcia, W.V.; Sanchez-Olguin, E.; Hulting, A.G.; Mallory-Smith, C. Target-site mutation associated with glufosinate resistance in italian ryegrass (Lolium perenne L. ssp. multiflorum). Pest Manag. Sci. 2012, 68, 1248-1254. [CrossRef] [PubMed]

5. Yu, Q.; Han, H.; Vila-Aiub, M.M.; Powles, S.B. Ahas herbicide resistance endowing mutations: Effect on ahas functionality and plant growth. J. Exp. Bot. 2010, 61, 3925-3934. [CrossRef] [PubMed]

6. Shaner, D.L.; Lindenmeyer, R.B.; Ostlie, M.H. What have the mechanisms of resistance to glyphosate taught us? Pest Manag. Sci. 2012, 68, 3-9. [CrossRef] [PubMed]

7. Petit, C.; Duhieu, B.; Boucansaud, K.; Délye, C. Complex genetic control of non-target-site-based resistance to herbicides inhibiting acetyl-coenzyme a carboxylase and acetolactate-synthase in alopecurus myosuroides huds. Plant Sci. 2010, 178, 501-509. [CrossRef] 
8. Busi, R.; Vila-Aiub, M.; Powles, S. Genetic control of a cytochrome p450 metabolism-based herbicide resistance mechanism in lolium rigidum. Heredity 2011, 106, 817-824. [CrossRef] [PubMed]

9. Feng, P.C.; Pratley, J.E.; Bohn, J.A. Resistance to glyphosate in lolium rigidum. Ii. Uptake, translocation, and metabolism. Weed Sci. 1999, 47, 412-415.

10. Ge, X.; d'Avignon, D.A.; Ackerman, J.J.; Sammons, R.D. Rapid vacuolar sequestration: The horseweed glyphosate resistance mechanism. Pest Manag. Sci. 2010, 66, 345-348. [CrossRef] [PubMed]

11. Gaines, T.A.; Zhang, W.; Wang, D.; Bukun, B.; Chisholm, S.T.; Shaner, D.L.; Nissen, S.J.; Patzoldt, W.L.; Tranel, P.J.; Culpepper, A.S. Gene amplification confers glyphosate resistance in amaranthus palmeri. Proc. Natl. Acad. Sci. USA 2010, 107, 1029-1034. [CrossRef] [PubMed]

12. Robertson, R.R. Physiological and Biochemical Characterization of Glyphosate Resistant Ambrosia trifida L.; Purdue University: West Lafayette, IN, USA, 2010.

13. Lespérance, M.A. Programmed Cell Death and Altered Translocation Cause Glyphosate Resistance in Giant Ragweed (Ambrosia trifida L.); University of Guelph: Guelph, ON, Canada, 2016.

14. Preston, C.; Wakelin, A.M.; Dolman, F.C.; Bostamam, Y.; Boutsalis, P. A decade of glyphosate-resistant lolium around the world: Mechanisms, genes, fitness, and agronomic management. Weed Sci. 2009, 57, 435-441. [CrossRef]

15. Bostamam, Y.; Malone, J.M.; Dolman, F.C.; Boutsalis, P.; Preston, C. Rigid ryegrass (Lolium rigidum) populations containing a target site mutation in epsps and reduced glyphosate translocation are more resistant to glyphosate. Weed Sci. 2012, 60, 474-479. [CrossRef]

16. Kaundun, S.S.; Dale, R.P.; Zelaya, I.A.; Dinelli, G.; Marotti, I.; McIndoe, E.; Cairns, A. A novel p1061 mutation in epsps and an unknown mechanism (s) act additively to confer resistance to glyphosate in a south african Lolium rigidum population. J. Agric. Food. Chem. 2011, 59, 3227-3233. [CrossRef] [PubMed]

17. Tani, E.; Chachalis, D.; Travlos, I.S. A glyphosate resistance mechanism in Conyza canadensis involves synchronization of epsps and abc-transporter genes. Plant Mol. Biol. Rep. 2015, 33, 1721-1730. [CrossRef]

18. Gressel, J. Evolving understanding of the evolution of herbicide resistance. Pest Manag. Sci. 2009, 65, 1164-1173. [CrossRef] [PubMed]

19. Sammons, R.D.; Gaines, T.A. Glyphosate resistance: State of knowledge. Pest Manag. Sci. 2014, 70, $1367-1377$. [CrossRef] [PubMed]

20. Peng, Y.; Abercrombie, L.L.; Yuan, J.S.; Riggins, C.W.; Sammons, R.D.; Tranel, P.J.; Stewart, C.N. Characterization of the horseweed (Conyza canadensis) transcriptome using gs-flx 454 pyrosequencing and its application for expression analysis of candidate non-target herbicide resistance genes. Pest Manag. Sci. 2010, 66, 1053-1062. [CrossRef] [PubMed]

21. Lai, Z.; Kane, N.C.; Kozik, A.; Hodgins, K.A.; Dlugosch, K.M.; Barker, M.S.; Matvienko, M.; Yu, Q.; Turner, K.G.; Pearl, S.A. Genomics of Compositae weeds: Est libraries, microarrays, and evidence of introgression. Am. J. Bot. 2012, 99, 209-218. [CrossRef] [PubMed]

22. Délye, C.; Duhoux, A.; Pernin, F.; Riggins, C.W.; Tranel, P.J. Molecular mechanisms of herbicide resistance. Weed Sci. 2015, 63, 91-115. [CrossRef]

23. Boyko, A.; Kovalchuk, I. Epigenetic control of plant stress response. Environ. Mol. Mutagen. 2008, 49, 61-72. [CrossRef] [PubMed]

24. Delye, C. Unravelling the genetic bases of non-target-site-based resistance (ntsr) to herbicides: A major challenge for weed science in the forthcoming decade. Pest Manag. Sci. 2013, 69, 176-187. [CrossRef] [PubMed]

25. Sahu, P.P.; Pandey, G.; Sharma, N.; Puranik, S.; Muthamilarasan, M.; Prasad, M. Epigenetic mechanisms of plant stress responses and adaptation. Plant Cell Rep. 2013, 32, 1151-1159. [CrossRef] [PubMed]

26. Bobadilla, R.; Berr, A. Histone methylation-a cornerstone for plant responses to environmental stresses? In Abiotic and Biotic Stress in Plants-Recent Advances and Future Perspectives; InTech: Vienna, Austria, 2016.

27. Hauser, M.-T.; Aufsatz, W.; Jonak, C.; Luschnig, C. Transgenerational epigenetic inheritance in plants. BBA Gene Regul. Mech. 2011, 1809, 459-468. [CrossRef] [PubMed]

28. Garg, R.; Chevala, V.N.; Shankar, R.; Jain, M. Divergent DNA methylation patterns associated with gene expression in rice cultivars with contrasting drought and salinity stress response. Sci. Rep. 2015, 5. [CrossRef] [PubMed]

29. Anthony, R.G.; Waldin, T.R.; Ray, J.A.; Bright, S.W.; Hussey, P.J. Herbicide resistance caused by spontaneous mutation of the cytoskeletal protein tubulin. Nature 1998, 393, 260-263. [CrossRef] [PubMed] 
30. Ward, S.M.; Webster, T.M.; Steckel, L.E. Palmer amaranth (Amaranthus palmeri): A review. Weed Technol. 2013, 27, 12-27. [CrossRef]

31. Travlos, I.; Chachalis, D. Assessment of glyphosate-resistant horseweed (Conyza canadensis L. Cronq.) and fleabane (Conyza albida willd. Ex spreng) populations from perennial crops in greece. Int. J. Plant Prod. 2013, 7 .

32. Hoagland, D.R.; Arnon, D.I. The water-culture method for growing plants without soil. In Circular; California Agricultural Experiment Station: Davis, CA, USA, 1950; Volume 347.

33. Chachalis, D.; Travlos, I. Glyphosate resistant weeds in southern europe: Current status, control strategies and future challenges. In Handbook of Herbicides: Biological Activity, Classification, and Health and Environmental Implications; Kobayashi, D., Watanabe, E., Eds.; Nova Science Publishers: Hauppauge, NY, USA, 2014; pp. 175-191.

34. Tani, E.; Chachalis, D.; Travlos, I.S.; Bilalis, D. Environmental conditions influence induction of key abc-transporter genes affecting glyphosate resistance mechanism in Conyza canadensis. Int. J. Mol. Sci. 2016, 17, 342. [CrossRef] [PubMed]

35. Aceituno, F.F.; Moseyko, N.; Rhee, S.Y.; Gutiérrez, R.A. The rules of gene expression in plants: Organ identity and gene body methylation are key factors for regulation of gene expression in Arabidopsis thaliana. BMC Genom. 2008, 9, 438. [CrossRef] [PubMed]

36. Jones, P.A. Functions of DNA methylation: Islands, start sites, gene bodies and beyond. Nat. Rev. Genet. 2012, 13, 484-492. [CrossRef] [PubMed]

37. Feng, J.; Zhou, Y.; Campbell, S.L.; Le, T.; Li, E.; Sweatt, J.D.; Silva, A.J.; Fan, G. Dnmt1 and dnmt3a maintain DNA methylation and regulate synaptic function in adult forebrain neurons. Nat. Neurosci. 2010, 13, 423-430. [CrossRef] [PubMed]

38. Lorincz, M.C.; Dickerson, D.R.; Schmitt, M.; Groudine, M. Intragenic DNA methylation alters chromatin structure and elongation efficiency in mammalian cells. Nat. Struct. Mol. Biol. 2004, 11, 1068-1075. [CrossRef] [PubMed]

39. Luco, R.F.; Pan, Q.; Tominaga, K.; Blencowe, B.J.; Pereira-Smith, O.M.; Misteli, T. Regulation of alternative splicing by histone modifications. Science 2010, 327, 996-1000. [CrossRef] [PubMed]

40. Choi, S.-W.; Friso, S. Epigenetics: A new bridge between nutrition and health. Adv. Nutr. Int. Rev. J. 2010, 1, 8-16. [CrossRef] [PubMed]

41. González, R.M.; Ricardi, M.M.; Iusem, N.D. Atypical epigenetic mark in an atypical location: Cytosine methylation at asymmetric ( $\mathrm{cnn}$ ) sites within the body of a non-repetitive tomato gene. BMC Plant Biol. 2011, 11, 94. [CrossRef] [PubMed]

42. Asensi-Fabado, M.-A.; Amtmann, A.; Perrella, G. Plant responses to abiotic stress: The chromatin context of transcriptional regulation. BBA Gene Regul. Mech. 2017, 1860, 106-122. [CrossRef] [PubMed] 